\title{
Research on Problems and Countermeasures of College Bilingual Instruction
}

\author{
Yuan FU \\ Wuhan Business University, Wuhan, 430056, China \\ email:627356365@qq.com
}

Keywords: Bilingual Instruction; Problems; Countermeasures

\begin{abstract}
Along with the rapid economic development and economy globalization, the ever-growing demand for high-level compound talents proficient in both professional skills and foreign languages directly contributes to the emergence of bilingual instruction in colleges. Compared to the long history of bilingual instruction in the west, Chinese bilingual instruction is still on the initial stage and is moving forward after some relative foreign theories. It is obviously the key and difficult points in our college teaching reform. However, there are a few problems in college bilingual instruction including people's misunderstanding, vague objectives, unreasonable distribution, faculty deficiency and stereotyped methods. Thus, this paper attempts to analyze the existing problems and accordingly propose some suggestions for improvement based on the connotation of bilingual instruction.
\end{abstract}

\section{Introduction}

Along with the rapid economy development and economy globalization after China joined in WTO, the demand for high-level compound talents proficient in both professional skills, foreign languages and intercultural communication is rapidly increasing. [1]To develop such talents to promote international communication and cooperation, the Ministry of Education released the document of Suggestions on Strengthening College Undergraduate Teaching and Improving Undergraduate Teaching Quality ([2001] 4) in 2001. And in 2005, the Ministry of Education issued the document of Suggestions on Further Strengthening College Undergraduate Teaching ([2005] 1) in 2005. [2] They both required undergraduate teaching to provide more public courses and specialized courses taught in foreign languages and to improve the quantity and quality of bilingual teaching courses, which undoubtedly challenge the talent training mode in college. [3] Bilingual instruction is playing an increasingly important role in education and management. However, there are also some problems as it is still in the primary stage. [4]Thus, this paper attempts to reflect some problems in recent bilingual teaching and accordingly proposes some corresponding suggestions based on the analysis of current situation of college bilingual instruction.

\section{Definition of Bilingual Instruction}

The word "bilingual" dates back to the 19th century when the world witnessed the wave of immigration. [5] To deal with the newly-emerging educational problems in multiracial regions and countries like Singapore, Indonesia, Mexico, Quebec in Canada and some American cities with the most immigrants, they all carried out bilingual teaching. According to the famous British dictionary Longman Dictionary for Applied Linguistics, the word "bilingual" is defined as follows:

A person who knows and uses two languages.

In everyday use the word bilingual usually means a person who speaks, reads, or understands two languages equally well (a balanced bilingual), but a bilingual person usually has a better knowledge of one language than of the other.

For example, he/she may:

Be able to read and write in only one language.

Use each language in different types of situation, e.g. One language at home and the other at 
work.

Use each language for different communicative purpose, e.g. One language for talking about school life and the other for talking about personal feeling.

To put it simply, "bilingual” means two languages. It means a situation in which people may or have to employ two languages to communicate when two or more races and cultures exist in the same region or country.

According to Longman Dictionary for Applied Linguistics, bilingual instruction is defined as "the use of a second or foreign language in school for the teaching of content subjects". [6] But in China, the heated discussion of acknowledged definition has never stopped until Wang Qiuhua, associate researcher in the Institute of Curriculum, the Ministry of Education, gives the brief definition that bilingual instruction means the direct use of a foreign language in school for the teaching of non-language subjects and the synchronous output of foreign languages and content knowledge. [7] It emphasizes the output and input of content knowledge and also tries to provide a platform for students to learn and use a second language so as to realize the ultimate goal that students can think in the way of first language and second language, can perfectly employ the language according to who they communicate with and where they work and can foster their ability and sense of intercultural communication.

\section{Problems of Chinese Bilingual Instruction}

In recent years, many colleges have employed bilingual instruction. However, there are many problems existing especially in local common colleges. The main problems are as follows:

A. Vague Objectives of Bilingual Instruction

Most colleges hold different ideas in the general goal of bilingual instruction. Some colleges hold the idea that professional learning is second to English enhancement and improvement in bilingual instruction, which results in the shift of teaching content from professional knowledge to foreign language. Many teachers attach great importance to the translation of textbook in the class and students are busy in taking notes of the translation and interpretation of some terms while having no time to learn professional knowledge[1]. Thus, bilingual instruction becomes pure language teaching which leaves professional knowledge and skills out and prevents students from free and innovative thinking.

B. Faculty Deficiency of Bilingual Instruction

Though many young college teachers are masters or even doctors, most of them always haven't gone abroad or specialized in foreign language for more than year. That means, they can do well in examinations and English wring and speaking, but they usually can not give bilingual instruction freely and easily. It is common nowadays that most college teachers excel in word retention, grammar, and reading while are weak in spoken English, listening and writing. Therefore, all-round developed teachers proficient with English listening, speaking, reading and writing and integrated use of English are urgently needed.

C. Gap among Students’ English Levels

The leading role of students in learning decides that the design of teaching activities should be student-centered and should pay much attention to students' ability to understand and absorb. Generally, the higher level of students' English, the better they can understand and absorb what they are taught and the better the bilingual instruction will be. With the college expansion of enrollment in recent years, students' quality is descending day by day. Consequently, students' different English levels largely hinder the development of bilingual instruction.

D. Shortage of Bilingual Teaching Textbooks

The selection of textbooks for bilingual instruction is complicated and prudent since it is connected with national teaching syllabus, curriculum standards and course setting. Some experts insist that bilingual class should employ original textbooks in foreign languages which can solidify students' English base, create an environment of using English and avoid the difference of English expression and the randomness of textbook editing and selection in each school. The Ministry of Education announces that colleges should employ advanced original textbooks in foreign languages 
for bilingual instruction. However, there are some problems in practice including teachers' limited access to textbooks in foreign languages, narrow coverage, too high price for students and so on.

\section{Corresponding Suggestions}

\section{A. Setting Teaching Goals}

Bilingual instruction aims to enable students to have a good grasp of professional knowledge and skills instead of simply improving their English. And its ultimate goal is to develop international talents who are proficient with professional knowledge and foreign languages are able to think in the way of Chinese and English and can perfectly employ the language according to who they communicate with and where they work. Teachers should reasonably decide the proportion of English teaching in each class according to students' English level. In short, to develop international and versatile talents excelling in intercultural communication based on their professional knowledge is the ultimate goal of bilingual instruction.

B. Enhancing the Construction of Teaching Staff

Bilingual instruction requires teachers to improve their quality and capacity. To enhance the construction of teaching staff, colleges can take actions mainly from three aspects. Firstly, it's a good choice for colleges to encourage and select masters to minor a second language. For instance, English majors are encouraged to minor a non-language subject while non-English majors to minor a language subject. Secondly, overseas training is another good way. Colleges should support teachers to take overseas training so as to introduce advanced teaching concept and running mode, improve teachers' quality and course teaching. Thirdly, colleges are supposed to introduce foreign teachers based on their conditions so as to provide a platform for students to enjoy native English.

C. Enhancing Students’ English Base

According to students' grasp of English in local colleges, the course learning in English is a bit complicated. Students are required to have the capability of using English to fully prepare for the bilingual class. It actually means that students should not only be able to read English materials and steadily follow the teachers, but also be able to answer questions and speak themselves out in English.

D. Combining Textbooks in Chinese and Foreign Language

It is true that original textbooks in foreign language obviously reflect the western logic, culture, thought and reasoning as well as advanced teaching principles and skills. However, they are not perfectly suitable for the Chinese situation. Thus, teachers should carefully select those textbooks not only in line with Chinese textbooks but also representing the developing trends of discipline. In details, they are required to comply with the overall teaching plan of certain major, the teaching requirements of certain course and the follow-up courses. Besides, to comply with the selected textbooks in foreign language, colleges should accordingly adjust teaching content of other courses. In a word, the selected textbooks in foreign language should not only enjoy practicality and pertinence, but also be consistent with Chinese textbooks and teaching contents.

\section{Conclusion}

Bilingual instruction is the inevitable trend of Chinese educational reform. However, there are still many problems and differences in theories and practice since it is on the initial stage. We should learn from the previous experience and accordingly take actions to promote the development of bilingual instruction. In summary, bilingual instruction is a complicated hard long-term work. Thus, we should learn from the previous experience, think deeply, set teaching goals and take immediate actions so as to promote its healthy steady development.

\section{Acknowledgement}

In this paper, the research was sponsored by Recruitment and Employment bilingual teaching quality project. 


\section{References}

[1] English plus: Issues in bilingual education. Cazden, C.B.,\& Snow, C.E. . 1990

[2] How long? A synthesis of research on academic achievement in a second language. V Collier. Tesol Quarterly. 1989

[3] The Role of Primary Language Development in Promoting Educational Success for Language Minority Students. Cummins,J. Schooling and Language Minority Students A Theoretical Framework . 1981

[4] Principles and Practice in Second Language Learning. Krashen,S. . 1984

[5] Education of the twenty-first century: New professionalism in lifelong learning, knowledge development and knowledge sharing[J]. Tom J. Weert. Education and Information Technologies. 2006 (3)

[6] A Case Study of an EFL Teacher's Type of Questions: An Investigation into Classroom Interaction[J] . Majid Farahian,Mehrdad Rezaee. Procedia - Social and Behavioral Sciences. 2012

[7] INTRODUCTION[J] . Younghee Sheen. Studies in Second Language Acquisition. 2010 (2) 